\title{
Influence of Childhood Exposure to a Farming Environment on Age at Asthma Diagnosis in a Population-Based Study
}

\author{
Heidi Andersén, (D) 'Pinja llmarinen,' \\ Jasmin Honkamäki, 'Leena E Tuomisto, ${ }^{2}$ \\ Hanna Hisinger-Mölkänen, (D) ${ }^{3}$ Helena \\ Backman, (iD ${ }^{4}$ Bo Lundbäck, ${ }^{5}$ Eva \\ Rönmark, ${ }^{4}$ Lauri Lehtimäki, (D) ${ }^{1}$ Anssi \\ Sovijärvi, ${ }^{3}$ Päivi Piirilä, ${ }^{3}$ Hannu \\ Kankaanranta (D) \\ 'Faculty of Medicine and Health Technology, \\ Tampere University, Tampere, Finland; \\ ${ }^{2}$ Department of Respiratory Medicine, \\ Seinäjoki Central Hospital, Seinäjoki, Etelä- \\ Pohjanmaa, Finland; ${ }^{3}$ Faculty of Medicine, \\ University of Helsinki, Helsinki, Uusimaa, \\ Finland; ${ }^{4}$ Department of Public Health and \\ Clinical Medicine, Umeå University, Umeå, \\ Norrbotten, Sweden; ${ }^{5}$ Department of Internal \\ Medicine, Krefting Research Center, \\ Sahlgrenska Academy, University of \\ Gothenburg, Gothenburg, Västra Götaland, \\ Sweden
}

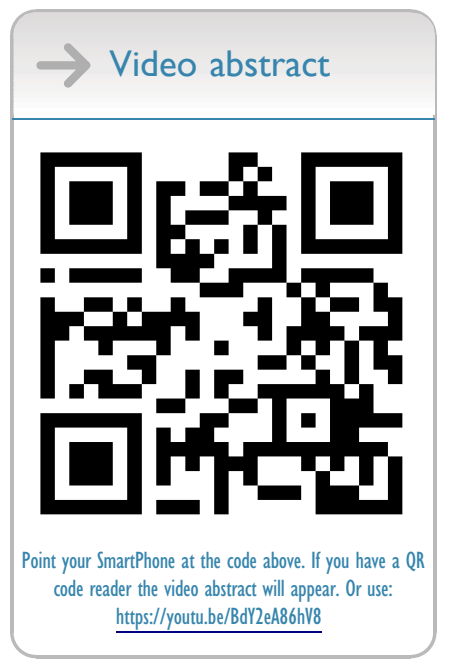

Correspondence: Heidi Andersén Faculty of Medicine and Health Technology, Tampere University, Kalevantie 4, Tampere, 33100 , Finland

Email heidi.andersen@tuni.fi
Purpose: Asthma is a heterogeneous disease, and factors associated with different asthma phenotypes are poorly understood. Given the higher prevalence of farming exposure and late diagnosis of asthma in more rural Western Finland as compared with the capital of Helsinki, we investigated the relationship between childhood farming environment and age at asthma diagnosis.

Methods: A cross-sectional population-based study was carried out with subjects aged 20 69 years in Western Finland. The response rate was 52.5\%. We included 3864 participants, 416 of whom had physician-diagnosed asthma at a known age and with data on the childhood environment. The main finding was confirmed in a similar sample from Helsinki. Participants were classified as follows with respect to asthma diagnosis: early diagnosis (0 11 years), intermediate diagnosis (12-39 years), and late diagnosis (40-69 years).

Results: The prevalence of asthma was similar both without and with childhood exposure to a farming environment (11.7\% vs $11.3 \%)$. Allergic rhinitis, family history of asthma, exsmoker, occupational exposure, and BMI $\geq 30 \mathrm{~kg} / \mathrm{m}^{2}$ were associated with a higher likelihood of asthma. Childhood exposure to a farming environment did not increase the odds of having asthma (aOR, 1.10; 95\% CI, 0.87-1.40). It did increase the odds of late diagnosis (aOR, 2.30; 95\% CI, 1.12-4.69), but the odds were lower for early (aOR, 0.49; 95\% CI, $0.30-0.80$ ) and intermediate diagnosis of asthma (aOR, 0.75; 95\% CI, 0.47-1.18).

Conclusion: Odds were lower for early diagnosis of asthma and higher for late diagnosis of asthma in a childhood farming environment. This suggests a new hypothesis concerning the etiology of asthma when it is diagnosed late.

Keywords: agriculture, early-diagnosed asthma, intermediate-diagnosed asthma, latediagnosed asthma, risk factors, phenotypes

\section{Summary}

- Late-onset asthma incidence was higher in agricultural Western Finland than in urban Southern Finland in a recent EpiLung study. Our study tries to find a reason for this difference.

- Childhood exposure to a farming environment and its microbiota has been shown to reduce the likelihood of allergic, often early-onset asthma. In contrast, data from the Finnish EpiLung study show that growing up in a farming environment increased the odds of asthma after age 40 .

- This result suggests a new hypothesis concerning the etiology of latediagnosed asthma. Therefore, based on the premise, children should be 
protected from harmful exposures but be exposed to diverse microbiota for good respiratory health.

\section{Introduction}

Asthma is a disease with several distinct phenotypes and endotypes. Age at asthma diagnosis is one way to divide asthma patients into phenotypes. ${ }^{1,2}$ We categorized participants into three groups: early- (0-11 years), intermediate- (12-39 years), and late-diagnosed (40-69 years) asthma. Respiratory viral infections are important triggers of asthma exacerbations at all ages. Nonetheless, it is unclear whether rhinovirus or respiratory syncytial virus are causally related to later atopic or nonatopic asthma. ${ }^{3}$

Early-diagnosed asthma patients are more often atopic and have a family history of atopy or asthma, thus having Type 2-predominant immunity (T2), responsiveness to glucocorticoids, and a good prognosis. ${ }^{4,5}$ For early-diagnosed asthma, reported risk factors include male sex, ${ }^{10}$ early abnormalities in lung function, ${ }^{11}$ atopy, ${ }^{7}$ air pollution, ${ }^{12}$ prenatal and household tobacco smoke, ${ }^{13}$ and obesity. ${ }^{14}$ Earlyand intermediate-diagnosed asthma have partly shared, but somewhat distinct, genetic risk factors, and genetics may play a more prominent role in young persons. ${ }^{15}$ Patients with intermediate- or late-diagnosed asthma are more often females with worse prognoses and low disease remission rates $^{6}$. In addition, they more often have persistent airflow limitation with either nonallergic T2 high- or non-T2 immunity. $^{7-9}$ For intermediate- and late-diagnosed asthma, known risk factors include female sex, smoking, occupational exposures, rhinitis, obesity, and early puberty. ${ }^{8,16}$ Although the risk factors for early-diagnosed asthma are well documented, there is still a lack of understanding of asthma risk factors in terms of the age at asthma onset, particularly risk factors associated with late-diagnosed asthma. Early- and late-diagnosed asthma may have different (eg, sex) or similar (eg, smoking, air impurities) risk factors.

Childhood exposure to farming environment reduces the risk for allergies and allergic asthma. However, most studies are based on a population $<50$ years of age, and thus, conclusions on the association of a childhood farming environment with late-diagnosed asthma cannot be drawn. ${ }^{17,18}$ High microbial diversity in the environment has been associated with lower asthma risk among children exposed to agricultural settings. ${ }^{18-20}$ Protective factors in the farming milieu are related to higher expression levels of innate immunity genes that contribute to the development of the immune system. ${ }^{21,22}$ Early- and late-diagnosed asthma are different in terms of driving immunity., ${ }^{2,8}$ Therefore, we hypothesized that the childhood environment might modify asthma risk differently for early-onset and late-onset asthma.

\section{Objectives}

This study aimed to compare factors associated with early-, intermediate-, and late-diagnosed asthma in a genetically homogenous population ${ }^{23}$ living in Western Finland, consisting of rural and suburban residents sharing the same social and healthcare services. The results were confirmed in a more urban and heterogeneous Helsinki cohort. Although there are several previous studies on asthma, this study is the first to date to evaluate both early-diagnosed and late-diagnosed phenotypes of asthma in the same setting, focusing on the role of childhood living conditions.

\section{Methods}

The study included a cross-sectional random sample of the population aged 20-69 years in February 2016 in Seinäjoki and Vaasa in Western Finland and Helsinki in Southern Finland as part of FinEsS (Finland-Estonia-Sweden) and EpiLung study. Nonresponders were often under 40 years and males. ${ }^{24,25}$

In Western Finland, 4173 participants responded in a postal survey, yielding a participation rate of $52.5 \%$ (Figure 1). To maintain a more homogenous population and childhood environment, we excluded 103 subjects with a primary language other than Finnish or Swedish, since they were likely to be immigrants. Altogether, 3864 subjects were included in the analyses.

The definition of late-diagnosed asthma varies among studies, from 12 years of age to $\geq 65$ years of age. ${ }^{26,27}$ As stated above, participants were categorized into three groups: early- (0-11 years), intermediate- (12-39 years), and latediagnosed (40-69 years) asthma. We decided not to use the term "age of onset," which might be different than the age at diagnosis and is seldom known. We used the presence and absence of allergic rhinitis to indicate asthma as allergic or nonallergic. $^{28}$ We analyzed the main results in Western Finland, a rural and farming region with a low migration rate, and validated the main result with the Helsinki cohort. ${ }^{25}$

\section{Definitions}

Physician-diagnosed asthma: Affirmative answer to "Has a doctor diagnosed you as having asthma?"

The age at asthma diagnosis: "What age were you when a doctor diagnosed you as having asthma?"

Childhood exposure to a farming environment: "Did you live on a farm during your first 5 years?" Because of urbanization, many aged 60 to 70 years grew up on a farm but had 

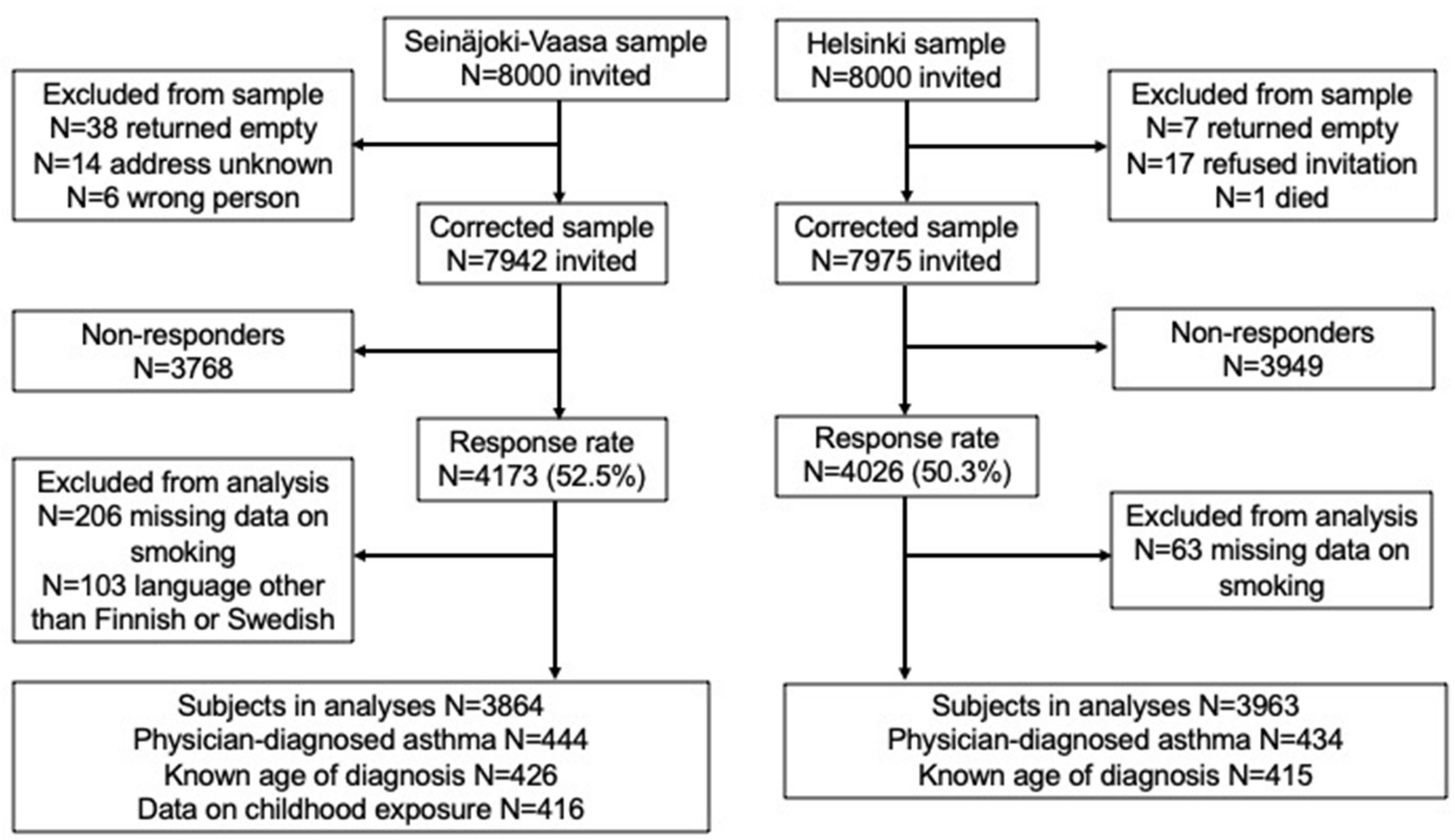

Figure I Flowchart depicting the study enrollment. The Seinäjoki-Vaasa sample was the main cohort, and Helsinki was the validation cohort.

different occupations later in life within the area. The farms used to be small and family-owned. Childhood exposure to farming, cattle, or hay work often continued during the entire childhood and occasionally even after the children moved away from the farm.

Physician-diagnosed Chronic Obstructive Pulmonary Disease (COPD): "Has a doctor diagnosed you as having chronic bronchitis, COPD, or emphysema?"

Family history of asthma: "Do you have a family history of asthma?"

Family history of allergic rhinitis: "Do you have a family history of allergic rhinitis?"

Occupational exposure to VGDF (vapors, gases, dust, or fumes): "Are you now being, or have you been, heavily exposed to gases, dust, or fumes at work?"

Physician-diagnosed allergic rhinitis: "Has a doctor diagnosed you as having allergic rhinitis caused by pollen (eg, birch, grass, mugwort)?" or "Has a doctor diagnosed you as having allergic rhinitis caused by dander, such as from a cat or dog?"

\section{Statistical Analysis}

Statistical analyses were performed using IBM SPSS Statistics software version 26 (IBM SPSS, Armonk, NY,
USA). The Kruskal-Wallis test was used to compare continuous variables with a nonnormal distribution between the three groups, and ANOVA was used to compare means. Pearson's chi-square test was used to compare categorical variables. A $p$-value $<0.05$ was considered significant.

Cox time to event analyses were done for age at asthma diagnosis for those with and without childhood exposure to farming environments with a comparison of hazard ratio (log rank). A null hypothesis was that the environment did not play a role in age at diagnosis.

Multivariable binary logistic regression analyses were performed to calculate odds ratios (ORs) with 95\% confidence intervals (CI) by using the dependent and independent variables described below.

Physician-diagnosed asthma: Independent variables were age, sex, allergic rhinitis, living on a farm during the first 5 years of life, family history of asthma, family history of allergy, smoking status, occupational exposure to VGDF, and current BMI.

Early-diagnosed asthma (age at diagnosis $<12$ years): Independent variables were sex, physiciandiagnosed allergy, living on a farm during the first 5 years of life, family history of asthma, and family history of allergy. 
Intermediate-onset asthma (age at diagnosis of 12-39 years) and late-onset asthma (age at diagnosis $\geq 40$ ): Independent variables in intermediate- and late-onset models were sex, allergic rhinitis, living on a farm during the first 5 years of life, family histories of asthma, family histories of allergy, smoking status, occupational exposure to VGDF, and current BMI.

\section{Results}

Demographics of those with and without childhood exposure to farming are shown in Table 1. Those with childhood exposure to a farming environment were older, had higher BMI, lower social status based on occupation, smoked less, had more occupational exposure, and exercised more than those without childhood exposure.

Table I Demographics of the 3767 Participants in Western Finland with Known Childhood Environment

\begin{tabular}{|c|c|c|c|}
\hline & $\begin{array}{l}\text { Childhood Non-Farming } \\
\text { Environment } n=2 \text { | } 43 \text { (56.9\%) }\end{array}$ & $\begin{array}{l}\text { Childhood Farming } \\
\text { Environment } n=1624 \text { (43.1\%) }\end{array}$ & $\mathbf{p}$ \\
\hline Female gender & II6I (54.2\%) & $805(49.6 \%)$ & 0.005 \\
\hline Mean age (SD) & $46(14.7)$ & $55(12.9)$ & $<0.001$ \\
\hline Median age & 48 & 59 & \\
\hline Mean BMI (SD) & $26.5(4.9)$ & $27.1(4.7)$ & $<0.001$ \\
\hline Median BMI & 25.8 & 26.3 & \\
\hline Family history of allergy & $742(34.6 \%)$ & $431(26.5 \%)$ & $<0.001$ \\
\hline Family history of asthma & $550(25.7 \%)$ & $421(25.9 \%)$ & 0.857 \\
\hline Current farmers & $25(1.4 \%)$ & $179(12.6 \%)$ & $<0.001$ \\
\hline Low socioeconomic status & $1033(58.1 \%)$ & $1003(71.1 \%)$ & $<0.001$ \\
\hline Physical activity more than 3 hours daily & $1036(51.6 \%)$ & $914(61.1 \%)$ & $<0.001$ \\
\hline Physical exercise more than $2-3$ times a week & 1525 (7I.7\%) & 1208 (75.0\%) & 0.023 \\
\hline Occupational exposure to VGDF & $670(31.8 \%)$ & $697(44.3 \%)$ & $<0.001$ \\
\hline Smoking status & & & $<0.001$ \\
\hline Never smokers & $1073(50.1 \%)$ & 911 (56.1\%) & \\
\hline Ex-smokers & $580(27.1 \%)$ & 449 (27.6\%) & \\
\hline Current smokers & $490(22.9 \%)$ & $264(16.3 \%)$ & \\
\hline Physician diagnosed asthma & 250 (II.7\%) & $184(11.3 \%)$ & 0.749 \\
\hline \multicolumn{4}{|l|}{ Age group } \\
\hline $20-39$ yrs & $109(14.2 \%)$ & $35(14.1 \%)$ & \\
\hline $40-59$ yrs & $82(9.8 \%)$ & 58 (9.7\%) & \\
\hline $60-69$ yrs & 59 (10.9\%) & 91 (II.7\%) & \\
\hline Current asthma medication & $250(11.7 \%)$ & 194 (II.9\%) & 0.792 \\
\hline Allergic rhinitis & $442(20.6 \%)$ & $240(14.8 \%)$ & $<0.001$ \\
\hline \multicolumn{4}{|l|}{ Age group } \\
\hline $20-39$ yrs & $209(27.1 \%)$ & $58(23.4 \%)$ & \\
\hline $40-59$ yrs & 170 (20.4\%) & $102(17.1 \%)$ & \\
\hline $60-69$ yrs & $63(11.7 \%)$ & $80(10.3 \%)$ & \\
\hline Physician diagnosed COPD & $48(2.2 \%)$ & $46(2.8 \%)$ & 0.248 \\
\hline \multicolumn{4}{|l|}{ Age group } \\
\hline $20-39$ yrs & $3(0.4 \%)$ & I (0.4\%) & \\
\hline $40-59$ yrs & $17(2.0 \%)$ & $14(2.3 \%)$ & \\
\hline $60-69$ yrs & 28 (5.2\%) & 31 (4.0\%) & \\
\hline
\end{tabular}

Notes: We excluded 97 with missing information on childhood exposure to farming environment. Low socioeconomic status was based on occupation and skill level. 
However, the prevalence of asthma was the same for both those exposed and not exposed to a childhood farming environment. The characteristics of the participants with asthma compared to those without asthma are shown in Table E1.

We analyzed associated factors for asthma with logistic regression. These were allergic rhinitis, family history of asthma, being an ex-smoker, occupational exposure to VGDF, and obesity, but not childhood exposure to a farming environment (Table 2).

\section{Early-, Intermediate- and Late-Diagnosed Asthma}

Of the responders with physician-diagnosed asthma, 114 (26.8\%) had early-diagnosed asthma, 173 (40.6\%) had intermediate-diagnosed asthma, and 139 (32.6\%) had latediagnosed asthma.

Early-diagnosed asthma was more frequent among males, and late- and intermediate-diagnosed asthma was more frequent among females (Table E2). Allergic

Table 2 Factors Associated with Asthma Assessed by Multivariable Logistic Regression Analyses

\begin{tabular}{|c|c|c|}
\hline & \multirow{2}{*}{\multicolumn{2}{|c|}{$\begin{array}{l}\text { Physician- } \\
\text { Diagnosed } \\
\text { Asthma }(n=444) \\
\text { *Adjusted }\end{array}$}} \\
\hline & & \\
\hline & OR & $95 \% \mathrm{Cl}$ \\
\hline Age & 1.00 & $0.99-1.01$ \\
\hline Female sex & 1.21 & $0.95-1.54$ \\
\hline Physician-diagnosed allergic rhinitis & 6.64 & $5.23-8.44$ \\
\hline Childhood exposure to farming environment & 1.10 & $0.87-1.40$ \\
\hline Family history of asthma & 2.38 & $1.88-3.02$ \\
\hline Family history of allergy & 0.90 & $0.70-1.16$ \\
\hline Nonsmoker (ref.) & & \\
\hline Ex-smoker & 1.54 & $1.19-1.99$ \\
\hline Current smoker & 1.21 & $0.89-1.64$ \\
\hline Occupational exposure to VGDF & 1.32 & $1.04-1.67$ \\
\hline BMI $<25 \mathrm{~kg} / \mathrm{m}^{2}$ (ref.) & & \\
\hline BMI $25-29.99 \mathrm{~kg} / \mathrm{m}^{2}$ & 0.87 & $0.67-1.14$ \\
\hline $\mathrm{BMI} \geq 30 \mathrm{~kg} / \mathrm{m}^{2}$ & 1.38 & $1.03-1.84$ \\
\hline
\end{tabular}

Notes: *The model was adjusted for all covariates shown in the table Study population $\mathrm{n}=3864$.

Abbreviations: $\mathrm{BMI}$, body mass index; $\mathrm{Cl}$, confidence interval; COPD, chronic obstructive pulmonary disease; ILC, innate lymphoid cells; OR, odds ratio; Th, helper T cells; VGDF, vapors, gases, dust, or fumes. rhinitis was most frequent in the early-diagnosed asthma group and the least frequent in the late-diagnosed asthma group. Current obesity was almost two times more frequent in late-diagnosed asthma than in early-diagnosed asthma. Participants with late-diagnosed asthma more often had occupational exposure to VGDF, a smoking history, and COPD. Additionally, the proportions of patients with childhood exposure to a farming environment and a current occupation within agriculture were higher in late- than in early- or intermediate-diagnosed asthma. Childhood exposure to a farming environment and late-diagnosed asthma seemed to correlate, and therefore we did further analyses. Among 444 participants with physician-diagnosed asthma, the number of patients with a known age at asthma diagnosis and data on childhood exposure to farming was 416 (93.7\%).

\section{The Age at Asthma Diagnosis}

These 416 patients were included in the following analyses to illustrate the connection between the childhood environment and age at asthma diagnosis. The mean ages of diagnosis were compared between those with and those without a childhood exposure to farming. The mean diagnosis age was higher for those with than for those without childhood exposure to farming environment (33.5 years vs 23.0 years; $p<0.001$ ) (Figure 2A). Cox survival analyses show that $50 \%$ were given their asthma diagnosis by the age of 37 years if exposed to childhood farming, compared to by the age of 20 years if not exposed to farming childhood environment, hazard ratio $0.60 \quad(0.50-0.73)$ (Figure 2B).

\section{Factors Associated with Asthma Age at Diagnosis Groups}

Marked differences were found in associated factors among different ages at asthma diagnosis in both the crude and adjusted analyses (Figure 3; Tables E3 and E4). Interestingly, those with childhood exposure to a farming environment had lower odds for early- and intermediate-diagnosed asthma but higher odds for latediagnosed asthma. This main result was validated in the Helsinki data, and the result was similar, childhood exposure had lower odds for early-diagnosed and higher odds for late-diagnosed asthma (Figure 3B, Table E5).

Because younger subjects are less likely to grow up on a farm due to urbanization and of course cannot have lateonset asthma, we performed two additional analyses. OR of intermediate-diagnosed asthma was analyzed for those 
A

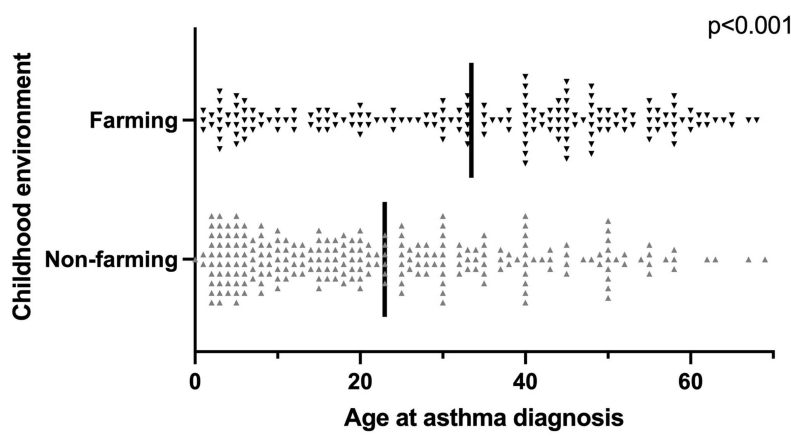

B

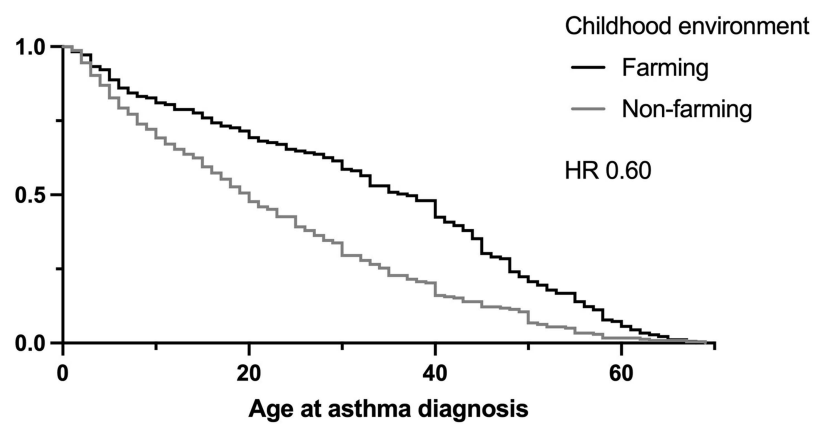

Figure 2 (A) Age at asthma diagnosis between subjects with farming and nonfarming childhood environments $(n=416)(A N O V A)$. Vertical lines indicate means $(B)$. Cox survival analyses of age at asthma diagnosis and childhood exposure to farming and nonfarming environments $(n=416)$.

over 40 years of age (Figure 3C, Table E6) and OR of latediagnosed asthma for those over 60 years and additionally adjusted for age (Figure 3C, Table E7).

\section{Sensitivity Analyses for the Main Result}

To exclude the possibility that data on subjects who were currently farming could affect our results, we performed a sensitivity analysis excluding participants who were currently or previously working within agriculture. Childhood exposure to a farming environment had higher odds of latediagnosed asthma in this model (Figure 4, Table E8).

We performed a sensitivity analysis, excluding participants with coexisting physician-diagnosed COPD because asthma and COPD share some risk factors and a considerable proportion of participants with late-onset asthma have coexisting COPD. In this model, childhood exposure to a farming environment continued to have higher odds for late-diagnosed asthma (Figure 4, Table E9). In separate analyses for allergic and nonallergic subjects, childhood exposure to a farming environment remained a risk factor for late-diagnosed asthma (Figure 4, Table E10).

\section{Discussion}

The main result of this study was that the same factor, childhood exposure to a farming environment, affected the probability of early- and late-diagnosed asthma differently. This exposure was associated with lower odds for asthma diagnosed before the age of 40 years but higher odds for asthma diagnosed after the age of 40 years among both allergic and nonallergic responders. The results remained the same after excluding a previous or current farming occupation or COPD.

\section{Other Associated Factors}

Females had higher odds of intermediate- and latediagnosed asthma, consistent with previous findings. ${ }^{4,50}$ Similar to an earlier study, late-diagnosed asthma was more often nonallergic. ${ }^{8}$ Ex-smoking and occupational exposures were associated with asthma, although they were not associated with age at asthma diagnosis. The previously reported attributable risk of occupational exposure ranges from $10 \%$ to $25 \%$ or more for adult asthma. ${ }^{51,52}$

\section{Childhood Farming Exposure Association with Late-Diagnosed Asthma}

Prevalence of asthma was similar with and without childhood exposure to farming in the age group 40-69 years. In contrast, there was some evidence linking childhood exposure to farming environment to late-diagnosed asthma. An earlier study showed a gradual increase in asthma diagnoses over time after farming exposures, supporting our finding. ${ }^{18}$ A limitation of earlier studies is that their lateonset asthma populations were small; participants were adults aged 20-44 years or 25-49 years. ${ }^{17,18}$ Asthma was associated with livestock in nonatopic farmers in Norway. ${ }^{29}$ A significant dose-response correlation was found between the amount of dust, fungal spores, bacteria, endotoxin, or ammonia and the development of nonatopic asthma. Nevertheless, the presence of livestock was reported to reduce asthma risk among atopic farmers. ${ }^{29}$ Adult farmers with respiratory disease more often have neutrophilic airway inflammation, ${ }^{30}$ and neutrophilic inflammation may also indicate T2-low asthma in addition to COPD remodeling. ${ }^{31}$ Occupational agricultural exposures are also associated with the development of chronic obstructive pulmonary disease. ${ }^{32,33}$ 
A

Childhood farming environment Western Finland

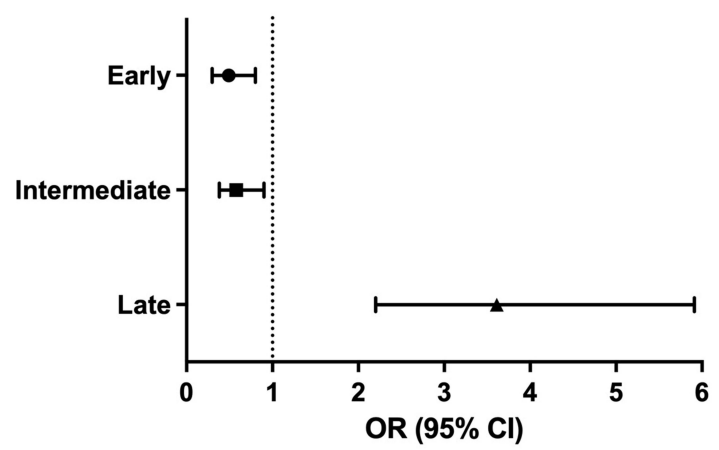

B

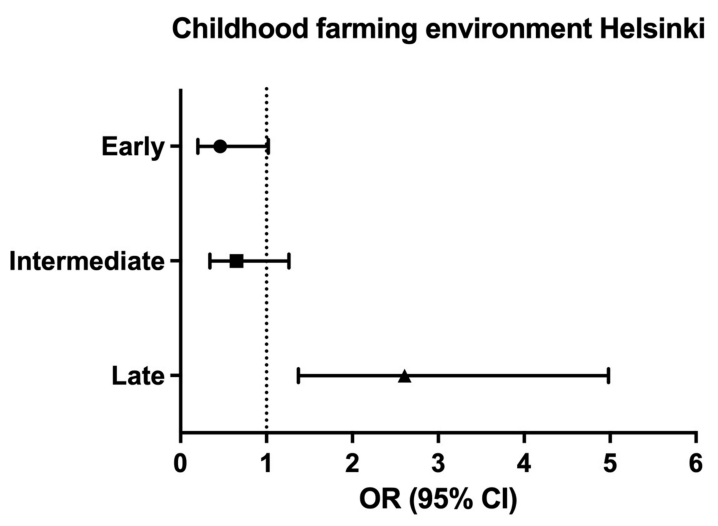

C

Childhood farming environment Western Finland (Age)

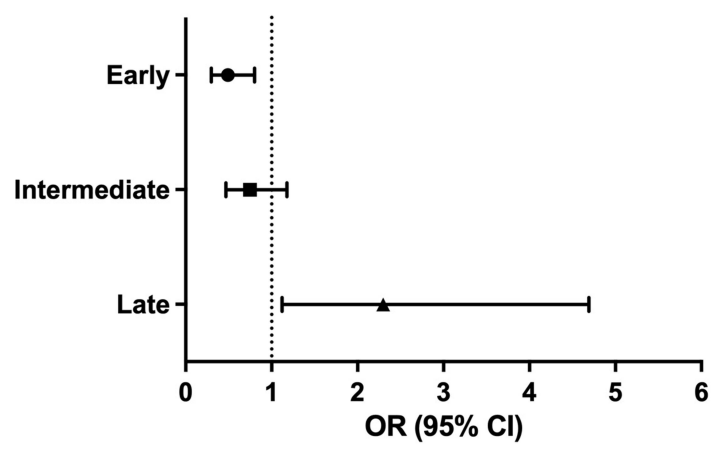

Figure 3 Association of age at asthma diagnosis with childhood exposure to a farming environment in Western Finland $(\mathbf{A})$, validation in the Helsinki population (B) and adjusted for age in Western Finland (C). For Figure A logistic regression analyses are shown in.Table E4, for Figure $B$ logistic regression analyses are shown in Table E5, and for Figure $\mathrm{C}$ in Tables E4, E6, and E7.

\section{Comparison with Earlier Childhood Farming Exposure Studies}

In previous prospective studies, a childhood farming environment protected against early-onset asthma. ${ }^{20,34,35}$ The OR of 0.49 in our study was similar in magnitude to that

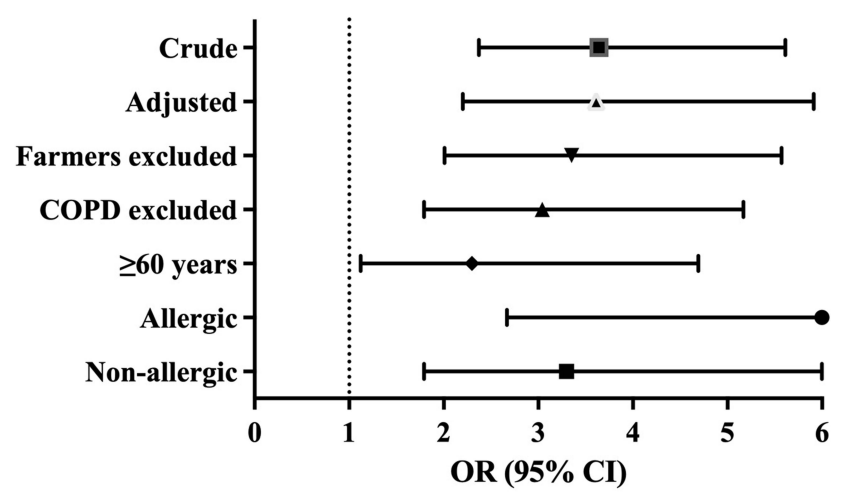

Figure 4 Association between childhood exposure to a farming environment of life and late-diagnosed asthma in all subjects and different subgroups in Western Finland. Models were adjusted for sex, allergic rhinitis, childhood exposure to a farming environment, family histories of asthma, family histories of allergy, smoking status, occupational exposure to vapors, gases, dust, or fumes, and current BMI. The crude results are shown in Table E3, and the adjusted models are presented in Tables E4, E7-E9, and EIO. The result remained in the adjusted analyses after exclusion of farmers (Table E8), COPD (Table E9), and those $<60$ years of age additionally adjusted for age (Table E7). Higher odds were seen for both allergic and nonallergic participants (Table EI0).

reported in studies from suburban Europe (OR 0.49) and alpine areas (OR 0.74). ${ }^{36,37}$ The childhood farming environment is related to higher expression levels of innate immunity genes and protects against asthma development during childhood. ${ }^{21}$ In an earlier study, long-term and early-life exposure to stables and farm milk was associated with the highest protective effect against asthma development in children. ${ }^{38}$ In another study, farm-like indoor microbiota in nonfarm homes also protected children from asthma development. ${ }^{39}$

However, not all farming exposures protect against asthma in children. ${ }^{21}$ Children with a larger relative environmental exposure to swine animal feeding operations had increased asthma risk (OR 1.51). ${ }^{40}$ In young adults aged 16-26 years, asthma risk for those born and raised on a farm was reduced (OR 0.50), whereas childhood exposure to large-scale swine and dairy feeding operations increased asthma risk (OR 3.37). ${ }^{41}$ Our finding is similar to those of studies that consider childhood exposure to farming as a protective factor against adult-onset asthma under 50 years of age. ${ }^{17,18}$

\section{Interpretation of the Results}

It has been proposed that the agricultural environment offers a rich microbial environment that reduces aberrant Th2 activation and reduces the risk of allergic asthma. ${ }^{18-20}$ Growing up on a farm leads to a lifelong protective effect against allergic rhinitis. ${ }^{42}$ In contrast, our study indicates that the protective effect on asthma might not be lifelong. 
On the other hand, farming offers exposure to environmental factors, leading to repeated injury of the airway epithelium that enhances mucosal permeability of foreign substances and further leads to epithelial barrier fragility. ${ }^{43}$ Thus, epithelial cytokines (eg, interleukin-25, interleukin33 , and thymic stromal lymphopoietin) released upon stimulation from environmental exposure can activate innate lymphoid cells (ILC2s) in an allergen-independent manner, leading to the development of nonallergic T2-high asthma. $^{44,45}$

ILCs are predominantly tissue-resident cells, and the perinatal period is critical for the distribution of ILCs within developing organs, especially ILC2s. ${ }^{46}$ It seems that the ILC pool residing in a given tissue is the result of waves of development from fetal to adult life (a phenomenon termed layered ontogeny) and may include different ILC subsets. ${ }^{47}$ ILC plasticity has been demonstrated in humans, and the change from ILC $3 s$ and ILC2s into ILC1s requires inflammatory cytokines (eg, interleukin-15, interleukin-23, interleukin-12, and interleukin-1b). ${ }^{48}$ This conversion is likely impacted by infections and other cytokine microenvironmental changes, such as in autoimmunity. ${ }^{48}$ Late-onset asthma is often considered to be mainly T2-low asthma; activation of Th1 and Th17 cells (type 1 and type 3 immunity, respectively) leads to neutrophil activation, and both T2 and non-T2 inflammatory pathways lead to airway remodeling. ${ }^{31,49}$

We hypothesize that in addition to microbial biodiversity, the childhood farming environment presents early harmful exposure to irritants that tease the epithelium and lead to epithelial barrier fragility. Over time, possibly the presence of cumulative exposure to various irritants (eg, occupational exposure, smoking) leads to layered ontogeny or ILC plasticity and generates an adult cell pool composed of cells of different origins. Cumulative exposure may lead to airway inflammation not mediated by ILC2s and to the development of T2-low late-onset asthma.

\section{Strengths and Limitations}

The strengths of the study were its large general population-based random sample and use of a validated questionnaire. Asthma diagnoses are based on objective lung function measurements and are reliable in Finland because of reimbursement policies. ${ }^{53}$ The age at asthma diagnosis corresponded with the asthma reimbursement data, in which $24.7 \%$ had early-diagnosed asthma, 28.3\% had intermediate-diagnosed asthma, and $47.0 \%$ had late- diagnosed asthma when an age distribution similar to that in this study was applied. ${ }^{49}$

As a limitation of the present study, recall bias concerning the age at asthma diagnosis is possible, considering that the recall periods are long. However, the start date of reimbursement is stated on reimbursement cards and is similar to age at diagnosis, reducing the possibility of recall bias. Furthermore, the age at asthma diagnosis might differ from the age at asthma onset; a person can have symptoms as a child but obtain a diagnosis later in life. Nonetheless, a previous study showed that the selfreported age at asthma onset in adults is accurate. ${ }^{54}$ Unfortunately in this kind of study, it is difficult to ascertain the connection between the timing of asthma diagnosis and timing of factors occurring later in life (eg, smoking, exposure to VGDF, and BMI), which may be a source of bias.

Another limitation was the response rate of $52.3 \%$. Young age groups and males were underrepresented, and in a similar Swedish cohort, nonresponders did not affect prevalence estimates. ${ }^{55}$ However, the response rate among those over 40 years of age was $61.7 \%$. A methodological weakness is that younger subjects are less likely to grow up on a farm because of increasing urbanization. These younger subjects cannot have late-onset asthma because of their young age, which can introduce bias. Analyses in a population aged over 40 years and over 60 years adjusted for age were conducted to address this bias due to the cross-sectional design. Even in these analyses, the childhood farming environment had higher odds of latediagnosed asthma. We performed sensitivity analyses to reduce the potential bias of misdiagnosis by excluding those with coexisting COPD or current farmers. In these analyses, the childhood farming environment still presented higher odds for late-diagnosis asthma.

Additionally, we validated the main finding in a more urban and heterogeneous Helsinki FinEsS survey. In Helsinki 434 subjects had physician-diagnosed asthma, and there were 415 responders for age at diagnosis. Of those, 131 (31.6\%) had early-diagnosed asthma, 184 $(44.3 \%)$ had intermediate-diagnosed asthma, and 100 (24.1\%) had late-diagnosed asthma. Of those with physician-diagnosed asthma with a known age at diagnosis, 184 (42.4\%) in Western Finland and 47 (11.5\%) in Helsinki had childhood exposure to a farming environment.

Our study population in Western Finland is genetically homogenous, ${ }^{23}$ but we cannot exclude genetic variations, such as in Toll-like receptor $6 .^{56}$ Because of selective 
migration, children do not receive protection against earlyonset asthma, because parents move away from the farming environment because of their asthma. ${ }^{57}$ Use of physician-diagnosed allergic rhinitis as a marker for allergies has limitations, because the association between allergic sensitization and rhinitis is strongest among the youngest

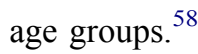

\section{Clinical Implications}

Asthma protection resulting from exposure to the farming environment might not be lifelong. A recent Finnish birth cohort study showed that a childhood farm environment protected from allergic sensitizations until middle age but it did not protect from new allergic sensitizations as an adult. ${ }^{59}$ One way forward could be a study boosting immunity with farm-like microbiota in adults to see whether it reduces asthma risk for non-T2 late-onset asthma, similar to protection seen in early-onset asthma. ${ }^{39}$ Consideration may be given to modifying adult immune and allergic responses by re-exposure of adults to farm environments without exposure to chemicals, gases, and fumes. Children should be protected from harmful exposures but be exposed to biodiversity, animals, and microbes for good respiratory health. Further studies are needed on which exact causative agents in the farming milieu are protective or harmful. Our study shows that a childhood farming environment is associated with late-diagnosed asthma, and this should be assessed when evaluating an older person for asthma.

\section{Conclusion}

We found that the asthma diagnosis age is essential for epidemiologic studies. The difference in median age at diagnosis was 17 years for those not exposed and exposed for childhood farming environment, however the prevalence of asthma as an adult was the similar in both groups. The childhood exposure to farming environment protected against asthma before the age of 40 years but had higher odds in late-onset asthma. Further prospective epidemiological and genetic studies are needed to resolve the risk factor heterogeneity among different age groups at asthma diagnosis.

\section{Data Sharing Statement}

All data generated or analyzed during this study are included in this published article (and its Supplementary Information File). According to ethical permission and data-protection laws of Finland, single-person data cannot be made available.

\section{Compliance with Ethical Standard}

Informed written consent was obtained from all individual participants. The Ethics Committee of the Department of Medicine of Helsinki University Central Hospital approved this study (approval number 200/13/03/00/15). The study was conducted in accordance with the Declaration of Helsinki.

\section{Acknowledgments}

We are grateful to Mr Antti Sepponen, technician, and Mrs Aino Sepponen, RN, for their input with the Western Finland FinEsS sample. We thank Dr Paula Pallasaho for participating in translating and modifying the original questions from the Finnish language form.

\section{Author Contributions}

All authors made a significant contribution to the work reported, whether that is in the conception, study design, execution, acquisition of data, analysis and interpretation, or in all these areas; took part in drafting, revising or critically reviewing the article; gave final approval of the version to be published; have agreed on the journal to which the article has been submitted; and agree to be accountable for all aspects of the work.

\section{Funding}

Supported by the Tampere Tuberculosis Foundation (Tampere, Finland), the Finnish Anti-Tuberculosis Association Foundation (Helsinki, Finland), the Research Foundation of the Pulmonary Diseases (Helsinki, Finland), the Allergy Research Foundation (Helsinki, Finland), Nummela Sanatorium Foundation (Helsinki, Finland), Nordic Council/NordForsk, the Competitive State Research Financing of the Expert Responsibility Area of Tampere University Hospital (Tampere, Finland) and the Medical Research Fund of Seinäjoki Central Hospital (Seinäjoki, Finland). The funding bodies had no role in planning, executing, drafting, or write-up of this study.

\section{Disclosure}

HA, JH, ER, AS, LL, PP have nothing to disclose. Dr Ilmarinen is an employee of GlaxoSmithKline. Dr Ilmarinen reports personal fees from Astra Zeneca, GlaxoSmithKline, Mundipharma, and Novartis outside the submitted work. Dr Tuomisto reports personal fees and nonfinancial support from Boehringer-Ingelheim, personal fees from Astra Zeneca, outside the submitted work. Dr Hisinger- 
Mölkänen is an employee of GlaxoSmithKline and reports personal fees from GlaxoSmithKline, outside the submitted work. Dr Backman reports personal fees from AstraZeneca and Boehringer-Ingelheim outside the submitted work. Dr Lundbäck reports grants from AstraZeneca, and ThermoFisher, personal fees from Sanofi, outside the submitted work. Dr Kankaanranta reports personal fees and nonfinancial support from AstraZeneca, Boehringer-Ingelheim, and Orion Pharma, personal fees from Chiesi, Novartis, Mundipharma, SanofiGenzyme, and GlaxoSmithKline, outside the submitted work. The authors report no other conflicts of interest in this work.

\section{References}

1. de Nijs SB, Venekamp LN, Bel EH. Adult-onset asthma: is it really different? Eur Respir Rev. 2013;22(127):44-52. doi:10.1183/090 59180.00007112

2. Wenzel SE. Asthma phenotypes: the evolution from clinical to molecular approaches. Nat Med. 2012;18(5):716-725. doi:10.1038/nm. 2678

3. Jartti T, Bønnelykke K, Elenius V, Feleszko W. Role of viruses in asthma. Semin Immunopathol. 2020;42:61-74. doi:10.1007/s00281020-00781-5

4. Bisgaard $\mathrm{H}$, Bonnelykke K. Long-term studies of the natural history of asthma in childhood. $J$ Allergy Clin Immunol. 2010;126 (2):187-197. doi:10.1016/j.jaci.2010.07.011

5. Paaso EMS, Jaakkola MS, Rantala AK, Hugg TT, Jaakkola JJK. Allergic diseases and asthma in the family predict the persistence and onset-age of asthma: a prospective cohort study. Respir Res. 2014;15:152. doi:10.1186/s12931-014-0152-8

6. Honkamäki J, Piirilä P, Hisinger-Mölkänen $\mathrm{H}$, et al. Asthma remission by age at diagnosis and gender in a population-based study. J Allerg Clin Immunol Pract. 2021;9(5):1950-1959. doi:10.1016/j.jaip.2020.12.015

7. Amelink M, De Nijs SB, De Groot JC, et al. Three phenotypes of adult-onset asthma. Allerg Eur J Allerg Clin Immunol. 2013;68 (5):674-680. doi:10.1111/all.12136

8. Ilmarinen P, Tuomisto LE, Kankaanranta H. Phenotypes, risk factors, and mechanisms of adult-onset asthma. Mediators Inflamm. 2015;2015:1-19. doi:10.1155/2015/514868

9. Tuomisto LE, Ilmarinen P, Niemelä $O$, Haanpää J, Kankaanranta T, Kankaanranta H. A 12-year prognosis of adult-onset asthma: Seinäjoki Adult Asthma Study. Respir Med. 2016;117:223-229. doi:10.1016/j.rmed.2016.06.017

10. Almqvist C, Worm M, Leynaert B. Impact of gender on asthma in childhood and adolescence: a GA 2LEN review. Allerg Eur J Allerg Clin Immunol. 2008;63(1):47-57.

11. Håland G, Carlsen KCL, Sandvik L, et al. Reduced lung function at birth and the risk of asthma at 10 years of age. $N$ Engl J Med. 2006;355(16):1682-1689. doi:10.1056/NEJMoa052885

12. Khreis H, Cirach M, Mueller N, et al. Outdoor air pollution and the burden of childhood asthma across Europe. Eur Respir J. 2019;54 (4):1802194. doi:10.1183/13993003.02194-2018

13. Silvestri M, Franchi S, Pistorio A, Petecchia L, Rusconi F. Smoke exposure, wheezing, and asthma development: a systematic review and meta-analysis in unselected birth cohorts. Pediatr Pulmonol. 2015;50(4):353-362. doi:10.1002/ppul.23037

14. Egan KB, Ettinger AS, Bracken MB. Childhood body mass index and subsequent physician-diagnosed asthma: a systematic review and meta-analysis of prospective cohort studies. BMC Pediatr. 2013;13 (1):1-3. doi:10.1186/1471-2431-13-121
15. Pividori M, Schoettler N, Nicolae DL, Ober C, Im HK. Shared and distinct genetic risk factors for childhood-onset and adult-onset asthma: genome-wide and transcriptome-wide studies. Lancet Respir Med. 2019;7(6):509-522. doi:10.1016/S2213-2600(19)30055-4

16. Peters U, Dixon AE, Forno E. Obesity and asthma. $J$ Allergy Clin Immunol. 2018;141(4):1169-1179. doi:10.1016/j.jaci.2018.02.004

17. Leynaert B, Neukirch C, Jarvis D, Chinn S, Burney P, Neukirch F. Does living on a farm during childhood protect against asthma, allergic rhinitis, and atopy in adulthood? $\mathrm{Am}$ J Respir Crit Care Med. 2001;164(10):1829-1834. doi:10.1164/ ajrccm.164.10.2103137

18. Douwes J, Travier N, Huang K, et al. Lifelong farm exposure may strongly reduce the risk of asthma in adults. Allergy. 2007;62 (10):1158-1165. doi:10.1111/j.1398-9995.2007.01490.x

19. Birzele LT, Depner M, Ege MJ, et al. Environmental and mucosal microbiota and their role in childhood asthma. Allerg Eur J Allerg Clin Immunol. 2017;72(1):109-119. doi:10.1111/all.13002

20. Von Ehrenstein OS, Von Mutius E, Illi S, Baumann L, Böhm O, Von Kries R. Reduced risk of hay fever and asthma among children of farmers. Clin Exp Allergy. 2000;30(2):187-193. doi:10.1046/j.13652222.2000.00801.x

21. Ege MJ, Frei R, Bieli C, et al. Not all farming environments protect against the development of asthma and wheeze in children. $J$ Allergy Clin Immunol. 2007;119(5):1140-1147. doi:10.1016/j.jaci.2007.01. 037

22. House JS, Wyss AB, Hoppin JA, et al. Early-life farm exposures and adult asthma and atopy in the Agricultural Lung Health Study. J Allergy Clin Immunol. 2017;140(1):249-256. doi:10.1016/j.jaci.20 16.09.036

23. Kerminen S, Havulinna AS, Hellenthal G, et al. Fine-scale genetic structure in Finland. G3 (Bethesda). 2017;7(10):3459-3468. doi: $10.1534 / \mathrm{g} 3.117 .300217$

24. Honkamäki J, Hisinger-Mölkänen H, Ilmarinen P, et al. Age- and gender-specific incidence of new asthma diagnosis from childhood to late adulthood. Respir Med. 2019;154:56-62. doi:10.1016/j.rmed. 2019.06.003

25. Hisinger-Mölkänen H, Pallasaho $P$, Haahtela $T$, Lindqvist A, Sovijärvi A, Piirilä P. The increase of asthma prevalence has levelled off and symptoms decreased in adults during 20 years from 1996 to 2016 in Helsinki, Finland. Respir Med. 2019;155:121-126. doi:10. 1016/j.rmed.2019.07.014

26. Miranda C, Busacker A, Balzar S, Trudeau J, Wenzel SE. Distinguishing severe asthma phenotypes: role of age at onset and eosinophilic inflammation. J Allergy Clin Immunol. 2004;113 (1):101-108. doi:10.1016/j.jaci.2003.10.041

27. Gibson PG, McDonald VM, Marks GB. Asthma in older adults. Lancet. 2010;376(9743):803-813. doi:10.1016/S0140-6736(10)61087-2

28. Pakkasela J, Ilmarinen P, Honkamäki J, et al. Age-specific incidence of allergic and non-allergic asthma. BMC Pulm Med. 2020;20(1):9. doi:10.1186/s12890-019-1040-2

29. Eduard W, Douwes J, Omenaas E, Heederik D. Do farming exposures cause or prevent asthma? Results from a study of adult Norwegian farmers. Thorax. 2004;59(5):381-386. doi:10.1136/ thx.2004.013326

30. Douwes J, Gibson P, Pekkanen J, Pearce N. Non-eosinophilic asthma: importance and possible mechanisms. Thorax. 2002;57:643-648. doi:10.1136/thorax.57.7.643

31. Kaur R, Chupp G. Phenotypes and endotypes of adult asthma: moving toward precision medicine. J Allergy Clin Immunol. 2019;144 (1):1-12. doi:10.1016/j.jaci.2019.05.031

32. Eduard W, Pearce N, Douwes J. Chronic bronchitis, COPD, and lung function in farmers: the role of biological agents. Chest. 2009;136 (3):716-725. doi:10.1378/chest.08-2192

33. May S, Romberger DJ, Poole JA. Respiratory health effects of large animal farming environments. $J$ Toxicol Environ Health Part B Crit Rev. 2012;15(8):524-541. doi:10.1080/10937404.2012.744288 
34. Wells AD, Poole JA, Romberger DJ. Influence of farming exposure on the development of asthma and asthma-like symptoms. Int Immunopharmacol. 2014;23(1):356-363. doi:10.1016/j.intimp.20 14.07.014

35. Wlasiuk G, Vercelli D. The farm effect, or: when, what and how a farming environment protects from asthma and allergic disease. Curr Opin Allergy Clin Immunol. 2012;12(5):461-466. doi:10.1097/ ACI.0b013e328357a3bc

36. Alfvén T, Braun-Fahrländer C, Brunekreef B, et al. Allergic diseases and atopic sensitization in children related to farming and anthroposophic lifestyle - the PARSIFAL study. Allerg Eur J Allerg Clin Immunol. 2006;61(4):414-421. doi:10.1111/j.1398-9995.2005.00939.x

37. Illi S, Depner M, Genuneit J, et al. Protection from childhood asthma and allergy in Alpine farm environments - the GABRIEL advanced studies. J Allergy Clin Immunol. 2012;129(6):1470-1477. doi:10. 1016/j.jaci.2012.03.013

38. Riedler J, Braun-Fahrländer C, Eder W, et al. Exposure to farming in early life and development of asthma and allergy: a cross-sectional survey. Lancet. 2001;358(9288):1129-1133. doi:10.1016/S01406736(01)06252-3

39. Kirjavainen PV, Karvonen AM, Adams RI, et al. Farm-like indoor microbiota in non-farm homes protects children from asthma development. Nat Med. 2019;25:1089-1095. doi:10.1038/s41591019-0469-4

40. Pavilonis BT, Sanderson WT, Merchant JA. Relative exposure to swine animal feeding operations and childhood asthma prevalence in an agricultural cohort. Environ Res. 2013;122:74-80. doi:10.1016/ j.envres.2012.12.008

41. Omland $\varnothing$, Hjort C, Pedersen OF, Miller MR, Sigsgaard T. Newonset asthma and the effect of environment and occupation among farming and nonfarming rural subjects. J Allergy Clin Immunol. 2011;128(4):761-765. doi:10.1016/j.jaci.2011.06.006

42. Eriksson J, Ekerljung L, Lötvall J, et al. Growing up on a farm leads to lifelong protection against allergic rhinitis. Allerg Eur J Allerg Clin Immunol. 2010;65(11):1397-1403. doi:10.1111/j.1398-9995.2010.02 397. $\mathrm{x}$

43. Gon Y, Hashimoto S. Role of airway epithelial barrier dysfunction in pathogenesis of asthma. Allergol Int. 2018;67(1):12-17. doi:10.1016/ j.alit.2017.08.011

44. Walker JA, Barlow JL, McKenzie ANJ. Innate lymphoid cells-how did we miss them? Nat Rev Immunol. 2013;13(2):75-87. doi:10.10 38/nri3349

45. Dhariwal J, Cameron A, Trujillo-Torralbo MB, et al. Mucosal type 2 innate lymphoid cells are a key component of the allergic response to aeroallergens. Am J Respir Crit Care Med. 2017;195(2):1586-1596. doi:10.1164/rccm.201609-1846OC

46. Schneider C, Lee J, Koga S, et al. Tissue-resident group 2 innate lymphoid cells differentiate by layered ontogeny and in situ perinatal priming. Immunity. 2019;50(6):1425-1438. doi:10.1016/j.immuni.20 19.04.019
47. Meininger I, Carrasco A, Rao A, Soini T, Kokkinou E, Mjösberg J. Tissue-specific features of innate lymphoid cells. Trends Immunol. 2020;41(10):902-917. doi:10.1016/j.it.2020.08.009

48. Colonna M. Innate lymphoid cells: diversity, plasticity, and unique functions in immunity. Immunity. 2018;48(6):1104-1117. doi:10.10 16/j.immuni.2018.05.013

49. Annunziato F, Romagnani C, Romagnani S. The 3 major types of innate and adaptive cell-mediated effector immunity. J Allergy Clin Immunol. 2015;135(3):626-635. doi:10.1016/j.jaci.2014.11.001

50. Melgert BN, Ray A, Hylkema MN, Timens W, Postma DS. Are there reasons why adult asthma is more common in females? Curr Allergy Asthma Rep. 2007;7(2):143-150. doi:10.1007/s11882-007-0012-4

51. Dykewicz MS. Occupational asthma: current concepts in pathogenesis, diagnosis, and management. J Allergy Clin Immunol. 2009;123 (3):519-528. doi:10.1016/j.jaci.2009.01.061

52. Smith AM. The epidemiology of work-related asthma. Immunol Allergy Clin North Am. 2011;31(4):663-675. doi:10.1016/j. iac.2011.07.009

53. Kankaanranta H, Tuomisto LE, Ilmarinen P. Age-specific incidence of new asthma diagnoses in Finland. J Allergy Clin Immunol Pract. 2017;5(1):189-191. doi:10.1016/j.jaip.2016.08.015

54. Torén K, Palmqvist M, Löwhagen O, Balder B, Tunsäter A. Selfreported asthma was biased in relation to disease severity while reported year of asthma onset was accurate. J Clin Epidemiol. 2006;59(1):90-93. doi:10.1016/j.jclinepi.2005.03.019

55. Räisänen P, Hedman L, Andersson M, et al. Non-response did not affect prevalence estimates of asthma and respiratory symptoms results from a postal questionnaire survey of the general population. Respir Med. 2020;173:106017. doi:10.1016/j.rmed.2020.106017

56. Lau MYZ, Dharmage SC, Burgess JA, et al. The interaction between farming/rural environment and TLR2, TLR4, TLR6 and CD14 genetic polymorphisms in relation to early- and late-onset asthma. Sci Rep. 2017;7:43681. doi:10.1038/srep43681

57. Timm S, Frydenberg M, Abramson MJ, et al. Asthma and selective migration from farming environments in a three-generation cohort study. Eur J Epidemiol. 2019;34(6):601-609.

58. Warm K, Hedman L, Lindberg A, Lötvall J, Lundbäck B, Rönmark E. Allergic sensitization is age-dependently associated with rhinitis, but less so with asthma. J Allergy Clin Immunol. 2015;136(6):1559-1565. doi:10.1016/j.jaci.2015.06.015

59. Haarala AK, Sinikumpu S, Vaaramo E, et al. A childhood farm environment protects from allergic sensitization until middle age but not from new-onset sensitization in adulthood: a 15 year longitudinal study. Int J Environ Res Public Health. 2021;18(7078):7078.

Journal of Asthma and Allergy

Dovepress

\section{Publish your work in this journal}

The Journal of Asthma and Allergy is an international, peer-reviewed open-access journal publishing original research, reports, editorials and commentaries on the following topics: Asthma; Pulmonary physiology; Asthma related clinical health; Clinical immunology and the immunological basis of disease; Pharmacological interventions and

new therapies. The manuscript management system is completely online and includes a very quick and fair peer-review system, which is all easy to use. Visit http://www.dovepress.com/testimonials.php to read real quotes from published authors.

Submit your manuscript here: https://www.dovepress.com/journal-of-asthma-and-allergy-journal 